\title{
Liver Injury and the Activation of the Hepatic Myofibroblasts
}

\author{
Joy X. Jiang • Natalie J. Török
}

Published online: 28 June 2013

(c) Springer Science+Business Media New York 2013

\begin{abstract}
Liver fibrosis is a wound healing process, the end result of chronic liver injury elicited by different noxious stimuli. Activated hepatic stellate cells or myofibroblasts and portal myofibroblasts are considered the main producers of the extracellular matrix in the liver. On liver injury, the quiescent stellate cells transdifferentiate into myofibroblasts, a process highlighted by the loss of vitamin A stores, upregulation of interstitial type collagens, $\alpha$-smooth muscle actin, matrix metalloproteinases, and proteoglycans, and the induction of cell survival pathways. Activation of hepatic stellate cells is a result of a complex interplay between the parenchymal cells, immune cells, extracellular matrix mechanics, and the extrahepatic milieu such as the gut microbiome. In this review we focus on the pathomechanism of stellate cell activation following chronic liver injury with the aim of identifying possible treatment targets for antifibrogenic agents.
\end{abstract}

Keywords Apoptosis - Sterile inflammation - Reactive oxidative species $\cdot$ Gut microbiota $\cdot$ miRNA

\section{Introduction}

Cirrhosis and its complications are the major causes of morbidity and mortality worldwide $[1,2]$. The only

\footnotetext{
J. X. Jiang · N. J. Török ( $\square)$

Division of Gastroenterology and Hepatology, Department of Internal Medicine, UC Davis Medical Center, $4150 \mathrm{~V}$ Street, Patient Support Services Bldg, Suite 3500, Sacramento, CA 95817, USA

e-mail: natalie.torok@ucdmc.ucdavis.edu
}

treatment currently available is liver transplantation however; the need for organs is continuously increasing and many patients die while on the waiting list. Despite significant improvement in our understanding of the fibrogenic process, there is still no FDA-approved treatment available.

Hepatic stellate cells (HSC) or fat-storing cells are normally localized in the perisinusoidal space and produce only small amounts of extracellular matrix (ECM) components for the formation of the basement membrane. When exposed to soluble factors or changes in matrix stiffness [3], they undergo morphological transition to myofibroblast-like cells [4-6]. The transdifferentiation is characterized by the loss of retinoid stores and acquisition of a myofibroblast phenotype, becoming highly proliferative and migratory and depositing type I collagen in the parenchyma [7]. Myofibroblasts express fibroblastic markers including $\alpha$-smooth muscle actin ( $\alpha$-SMA), and produce transforming growth factor $\beta$ (TGF- $\beta$ ), plateletderived growth factor, connective tissue growth factor, and other cytokines. A change in mechanical tension is also an important initiating factor in HSC activation. When the matrix stiffness changes, TGF- $\beta_{1}$ becomes activated and is released from its latent form, and this results in an increase in $\alpha$-SMA expression in HSCs [8]. Activated HSCs also express a combination of matrix metalloproteinases (MMPs) and their specific tissue inhibitors (TIMPs) [9]. In the fibrotic liver, HSCs produce pro-MMP-2 and membrane type $1 \mathrm{MMP}$, which drive pericellular generation of active MMP-2 and local degradation of the normal liver matrix. In addition, there is a marked increase in the expression of TIMP-1, leading to the inhibition of degradation of fibrillar liver collagens [10]. Portal fibroblasts are located in the portal area and under physiological conditions regulate the normal ECM turnover [11]. They are a 
cell population distinct from HSCs as they express elastin, fibulin-2, and glycophosphatidylinositol-linked glycoprotein (Thy1.1) but do not store vitamin A and are negative for glial fibrillary acidic protein, desmin, or cytoglobin [12]. Portal fibroblasts are an important source of TGF- $\beta$ and ECM during cholestatic liver injury [13, 14].

The common, key initiating factor of liver fibrogenesis is a persistent injury to the parenchymal cells. The cause could be toxic (alcohol, $\mathrm{CCl}_{4}$ ), metabolic (lipoapoptosis in nonalcoholic steatohepatitis, NASH), viral (hepatitis C virus and hepatitis B virus), cholestatic injury (primary biliary cirrhosis or sclerosing cholangitis), or a genetic defect (e.g., accumulation of misfolded $\alpha_{1}$-antitrypsin) and could result initially in the dysfunction of the epithelial cells with adaptive stress responses, and eventually culminate in cell death by apoptosis or necrosis [15]. Induction of such pathways during cell stress can generate reactive oxygen species (ROS) and inflammatory cytokines and chemokines which are profibrogenic and/or induce sterile inflammation, which leads to the propagation of injury.

\section{The Role of Hepatocyte Stress, Adaptive Responses, and Cell Death in Fibrosis}

Hepatocytes are constantly exposed to cellular stress and are equipped with efficient adaptive pathways to maintain homeostasis. Recent studies suggest that during NASH, dysregulation of insulin signaling, $\beta$-oxidation, and an increased influx and uptake of free fatty acids from the adipose tissue result in the accumulation of saturated fatty acids in hepatocytes, which is the major cause of lipotoxicity $[16,17]$. Lipotoxicity activates endoplasmic reticulum (ER) stress pathways and the unfolded protein response in an attempt to reestablish homeostasis. This may result in a translational arrest, the induction of protein folding and degradation, and the activation of autophagy. Autophagy in hepatocytes occurs as macroautophagy or chaperonemediated autophagy, whereby the degradation of damaged organelles limits the extent of injury [18]. Autophagy was recently shown to confer a resistance to TNF- $\alpha$-mediated cell death of hepatocytes by inhibiting caspase 8 activation and the mitochondrial pathway of apoptosis [19].

Prolonged and persistent ER stress, however, can cause failure of the adaptive mechanisms and the induction of the c-Jun N-terminal kinase (JNK), apoptosis-signal-regulating kinase 1 (ASK1), and the transcription factor CCAAT/ enhancer binding homologous protein (CHOP), launching apoptotic cascades $[20,21]$. The association between ER stress and apoptotic responses has been recognized not only in NASH but also in alcoholic liver disease $[22,23]$ and viral hepatitis $[24,25]$.
Apoptosis of hepatocytes can also be elicited by extrinsic signals such as TNF- $\alpha$, FasL (CD95L), and TNFrelated apoptosis-inducing ligand (TRAIL), which are well-characterized inducers of hepatocyte death. The cell death pathways during liver injury are described in detail in the excellent reviews of Reinehr and Haussinger [26] and Guicciardi and Gores [27•].

The paracrine effects of the dying cells and the fate of apoptotic cells deserve attention as cell death was shown to induce the activation of HSCs by multiple mechanisms. Apoptotic cells can release ATP or UTP into the extracellular milieu, serving as bait for phagocytic cells and causing phagocytes to bind to their prey via the purinergic $\mathrm{P} 2 \mathrm{Y}$ receptor [28]. HSCs were also shown to express P2Y receptors, and during their activation the expression of $\mathrm{P} 2 \mathrm{Y}$ receptor subtypes is altered. As activation of $\mathrm{P} 2 \mathrm{Y}$ receptors, especially $\mathrm{P} 2 \mathrm{Y} 6$, in the activated HSC regulates type I procollagen $\alpha_{1}$ transcription, it could be an attractive target for antifibrogenic strategies [29].

Apoptotic cells could be engulfed by the professional phagocytes, the Kupffer cells, by efferocytosis, or by the HSCs. Phagocytosis of the apoptotic bodies activates NADPH oxidase 2, superoxide production, and in the HSCs the type I collagen $\alpha_{1}$ promoter activity, and the production TGF- $\beta$ [30], whereas in Kupffer cells it stimulates death ligand expression [31]. Apoptotic bodies contain DNA and are the source of unmethylated cytosine-phosphate-guanosine ( $\mathrm{CpG})$ - DNA motifs that are recognized by Toll-like receptor (TLR) 9. Engagement of TLR9 in turn activates signaling cascades resulting in the production of type I collagen and the profibrogenic cytokine TGF- $\beta$ [32]. In a mouse model of NASH, TLR9 activation induced production of IL- $1 \beta$ by the Kupffer cells, leading to inflammation and fibrosis [33]. Elucidating the time course and the hierarchy of these pathways is essential in order to develop targets for fibrosis treatment (Fig. 1).

\section{The Role of Sterile Inflammation}

Noninfectious stimuli such as chronic cholestasis, alcoholic or nonalcoholic hepatitis, ischemia/reperfusion, and drug toxicity can cause damage to hepatocytes in the absence of exogenous pathogens. The consequent sterile inflammation is characterized by the release of endogenous damageassociated molecular patterns (DAMPs) and the activation of cellular pattern recognition receptors (PRRs), which result in the production of proinflammatory cytokines and the recruitment of immune cells to the site of injury [34•, 35]. Sterile inflammation results in the assembly of a cytosolic protein complex, the inflammasome, with the activation of the caspase 1 , and the secretion of IL-1 $\beta$, IL18 , and other cytokines [36]. The redox state of cells is an 


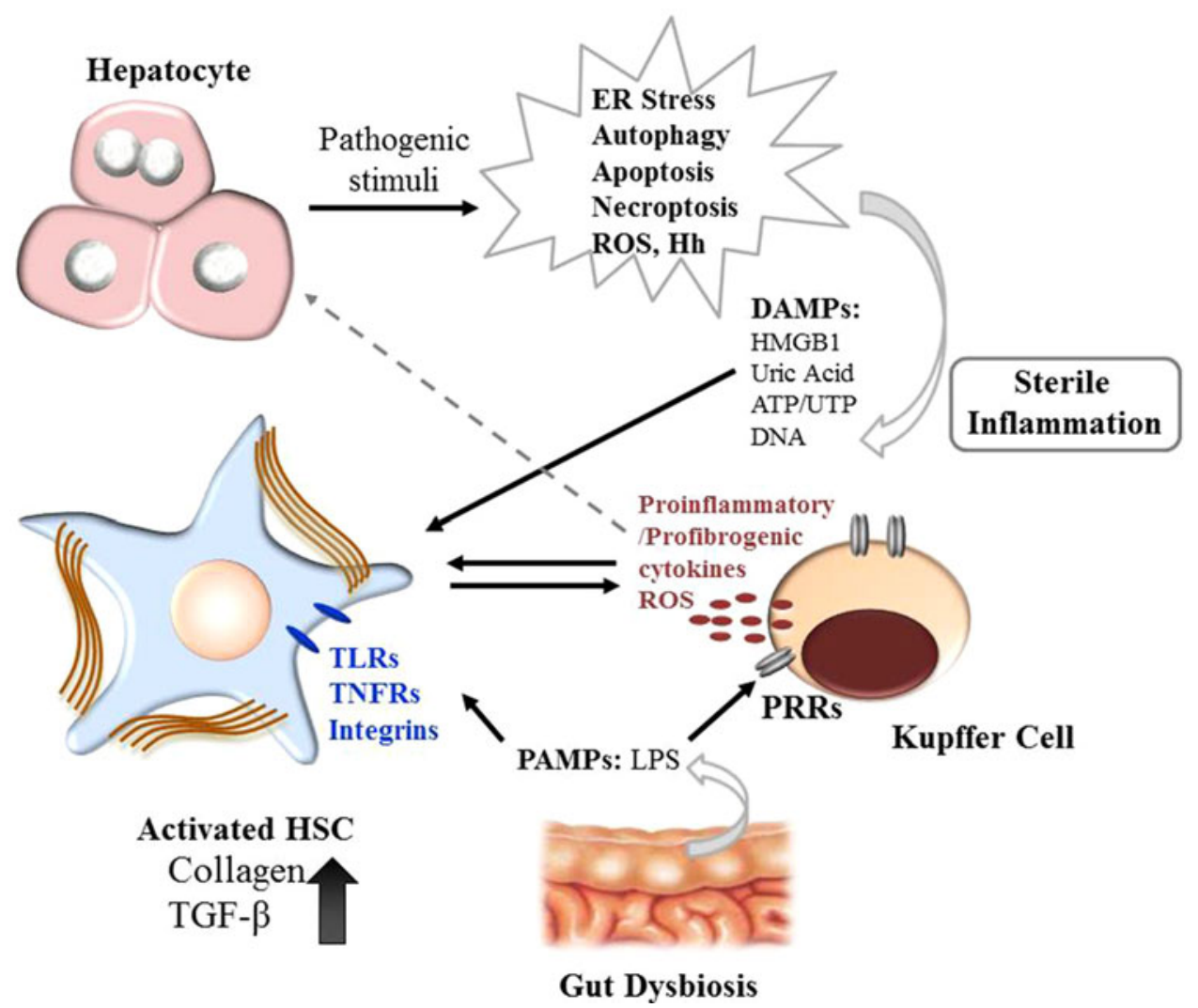

Fig. 1 Mechanism of liver-injury-mediated hepatic stellate cell (HSC) activation. Under pathologic conditions, hepatocytes first initiate adaptive responses such as induction of endoplasmic reticulum $(E R)$ stress and the unfolded protein response, and the induction of autophagy. After prolonged insult, however, hepatocytes undergo apoptosis or necrosis, and during the latter they release damageassociated molecular patterns (DAMPs), which react with pattern recognition receptors $(P R R s)$ on the target cells, to launch the sterile inflammation responses. This leads to inflammasome formation and the production of proinflammatory and profibrogenic cytokines, and

important modulator of inflammasome activation as it determines the efficiency of the activation, and downstream signals [37].

DAMPs that play a role in liver injury include the high mobility group box1 (HMGB1), galectins, ATP, uric acid, and extracellular DNA. The role of these DAMPs in sterile inflammation was recently reviewed in detail by Kubes and Mehal [38••]. DAMPs play a major role in the recruitment of inflammatory cells. Recruitment of neutrophils is a hallmark of progressive NASH and alcoholic and autoimmune hepatitis, and portends a poor prognosis. Neutrophils responding to sterile inflammation were found to be highly migratory through the sinusoids toward the focus of tissue necrosis, ultimately infiltrating the area of the damage [39]. Recently, Wang et al. [40] showed that HMGB1 induced IL-23 production via the activation of TLR4 in macrophages in the acetaminophen-overdosed mouse model; this in turn activated hepatic $\gamma \delta \mathrm{T}$ cells to release IL-17A, a the recruitment of inflammatory cells. DAMPs from injured hepatocytes may directly activate HSCs by the engagement of Toll-like receptors (TLRs) on HSCs. Compounding these events, dysbiosis and increased permeability of the gut also contribute to fibrosis by releasing high levels of lipopolysaccharide (LPS), a pathogenassociated molecular pattern $(P A M P)$ that induces macrophage and HSC activation via TLR4 signaling. Hh hedgehog, HMGB1 high mobility group box $1, R O S$ reactive oyxgen species, $T G F \beta$ transforming growth factor $\beta, T N F R$ TNF alpha receptor

potent inducer of neutrophil infiltration. In a different study using the alcohol diet model, HMGB1 was shown to attenuate macrophage efferocytosis, thereby facilitating secondary necrosis and perpetuating injury [41].

Galectins, a group of $\beta$-galactoside-binding lectins, are classified as DAMPs [42]. Galectin-3 has been shown to play an important role in liver diseases as animals deficient in galectin-3 were protected from fibrotic stimuli and acute liver injuries [43-48]. It is expressed mainly in macrophages and cholangiocytes in normal livers, but is upregulated and secreted from the myofibroblasts in the cirrhotic liver [43, 44]. Galectin-3 is a chemoattractant for macrophages [42], and plays a role in their alternative activation $[49,50]$.

Targeting the inflammasomes could be a promising therapeutic approach in NASH and alcoholic steatohepatitis. For instance, caspase $1^{-/-}$mice were protected against high-fat-diet-induced steatosis, inflammation, and early fibrosis [51]. In a different study, caspase 1 was 
responsible for the induction of IL-1 $\beta$ signaling, which was mediated by the IL-1 receptor, and IL-1 receptor antagonism improved the inflammasome-dependent alcoholic steatohepatitis in mice [52].

\section{The Role of Hepatic Immune Regulation}

There is extensive experimental evidence associating fibrosis with $\mathrm{T}$ helper type $2\left(\mathrm{~T}_{\mathrm{h}} 2\right)$ cell differentiation, characterized by the production of the cytokines IL-4 and IL-13 and the induction of myofibroblast collagen production [53] [54]. IL-13 was shown to be involved in fibrosis induced by hepatitis $\mathrm{C}$ virus [53], and in schistosomiasis [5], and the $\mathrm{T}_{\mathrm{h}} 2$ cytokines also regulate the alternative activation of macrophages [55]. Recently, IL17-producing effector $\mathrm{CD} 4^{+} \mathrm{T}$ ( $\mathrm{T}$ helper type 17) cells have been discovered regulating hepatic fibrosis [56]. IL-17 stimulated Kupffer cells to express the inflammatory cytokines IL-6, IL- $1 \beta$, and TNF- $\alpha$ and the fibrogenic mediator TGF- $\beta_{1}$. IL-17 also directly stimulated HSCs to express type I collagen via signal transducer and activator of transcription 3. Using IL-22 in these studies was shown to attenuate fibrosis.

Natural killer (NK) cells in the liver, on the other hand, have been described as antifibrotic by clearing active HSCs and producing the antifibrotic cytokine interferon- $\gamma$ (IFN $\gamma$ ) [57]. With use of an NK cell-HSC co-culture system, NK cells were shown to selectively kill the early activated HSCs but not the quiescent or fully activated myofibroblasts. A possible explanation for this is that transitional activation of HSCs causes the release of retinoic acid from HSCs, which induces the expression of retinoic acid inducible gene1 (REA1), an NK cell activator [58]. IFN $\gamma$ mainly produced by $\mathrm{T}$ helper type $1\left(\mathrm{~T}_{\mathrm{h}} 1\right)$ and NK cells is known to be proapoptotic to active HSCs, partially via the activation of the NK cell receptor group 2 member D (NKG2D) and the downstream activation of signal transducer and activator of transcription 1 [59]. Animal studies have shown that alcohol consumption blunts the IFN $\gamma /$ NKG2D transduction activity, thereby enhancing HSC survival and causing propagation of fibrosis [60]. However, IL-10 and TGF- $\beta$ were shown to inhibit the antifibrotic effects of NK cells especially during chronic alcohol consumption $[61,62 \cdot]$.

NK T (NKT) cells may have diverging roles in acute injury and fibrosis. NKT cells were protective in acute $\mathrm{CCl}_{4}$-induced injury, but potent NKT activation (induced by $\alpha$-galactosylceramide) exacerbated the injury [63]. In chronic $\mathrm{CCl}_{4}$-induced injury, invariant NKT (iNKT) cells were protective in the early stage but not in the late stage, and depletion of NKT cells showed no effects. A possible explanation is that the active iNKT cells produce both $T_{h} 1$ cytokines and $T_{h} 2$ cytokines [63]. In mice receiving the methionine choline deficient diet (MCD), the activation of hedgehog $(\mathrm{Hh})$ signaling induced CXCL16, an NKT cell chemoattractant. The accumulation of NKT cells accompanied by Hh induction was also found in cirrhotic NASH patients [64]. Recently, it was shown that the ligandreceptor interaction between CXCL16 and its receptor CXCR6 was crucial for the accumulation of NKT cells in the $\mathrm{CCl}_{4^{-}}$and MCD-induced fibrosis. The $\mathrm{CXCR6}^{-1-}$ mice were resistant to these stimuli, and the fibrotic phenotype was reestablished by the adoptive transfer of wild-type NKT cells [65]. It will be of interest to see further studies on how the roles of NK and NKT cells are integrated in fibrogenesis and whether their activation is dependent on the stage of fibrosis.

\section{The Role of Oxidative Stress}

Virtually all known causes of liver disease can lead to oxidative stress. In physiological settings, the cytotoxic potential of ROS is buffered by the different scavenging and antioxidant systems, including glutathione- and thiolcontaining proteins, superoxide dismutases, catalases, peroxiredoxins, and thioredoxin. Oxidative radicals can promote hepatocyte oncotic necrosis, apoptosis, or necroptosis by inducing mitochondrial dysfunction [66]. Beside direct cytotoxicity, ROS can induce a sensitizing effect to prolonged insults, or induce the generation of proinflammatory mediators. Oxidative radicals can thus be indirectly (via hepatocyte damage) or directly (Kupffer cell and HSC activation) profibrogenic [67, 68]. Furthermore, HSC activation can result from osteopontin, an ROS-sensitive, ECM cytokine which was recently shown to induce collagen production involving integrin $\alpha_{\mathrm{v}} \beta_{3}$ engagement and phosphoinositide 3-kinase/phosphorylated Akt/nuclear factor $\kappa \mathrm{B}(\mathrm{NF}-\kappa \mathrm{B})$ signaling [69].

ROS production in myofibroblasts occurs in response to profibrogenic mediators, including platelet-derived growth factor, TGF- $\beta$, leptin, and angiotensin II [70], induction of ER stress, and autophagy in HSCs [71], and by the phagocytosis of apoptotic debris in Kupffer cells and myofibroblasts [30]. In general, ROS can be generated via the mitochondrial electron chain, activation of cytochrome $\mathrm{P} 450$, arachidonic acid oxidation, xanthine oxidase activation, and the induction of the nicotinamide adenine dinucleotide phosphate (NADPH) oxidases. Activation of the phagocytic (NOX2 [68], [30]) or nonphagocytic (NOX1 [72, 73] and NOX4 [74]) forms of NADPH oxidases is the major source of ROS in the myofibroblasts and the induction of profibrogenic pathways. ROS are also important second messengers, regulating signaling pathways leading to cell survival of myofibroblasts [75, 76]. 
As NADPH oxidase activation may represent a core pathway in fibrosis, NOX inhibitors are emerging as targets for antifibrotic therapy. Recently, use of an inhibitor to NOX1/NOX4 has shown promise to prevent fibrosis progression in the $\mathrm{CCl}_{4}$ and bile duct ligation (BDL) models $[77,78]$.

\section{Intrinsic Metabolic Pathways and HSC Activation}

Chronic liver injury is intimately linked to the modulation of intrinsic metabolic pathways in HSCs and thereby to their activation and cell fate. Dying hepatocytes release hedgehog $(\mathrm{Hh})$ ligands that activate $\mathrm{Hh}$ signaling in the neighboring cells [79]. Hh ligands are developmental morphogens that control progenitor cell fate, liver repair and regeneration, and wound healing [80, 81•]. An interesting feature of Hh signaling in HSCs is the induction of glycolytic pathways during the transdifferentiation of quiescent HSCs into myofibroblasts, causing lactate accumulation since gluconeogenesis and lipogenesis are suppressed [82]. Inhibitors of Hh signaling or glycolysis or lactate accumulation converted myofibroblasts to quiescent HSCs, and conditional disruption of $\mathrm{Hh}$ signaling in myofibroblasts reduced the numbers of glycolytic myofibroblasts and liver fibrosis in mice. Targeting Hh signaling could thus be a promising therapeutic strategy.

Loss of retinoids from HSCs is a hallmark of myofibroblastic transdifferentiation. Recently autophagy emerged as a mechanism involved in lipid loss in HSCs, providing energy for their activation [83]. Autophagy-deficient HSCs were unable to process lipid droplets by acid lipases, resulting in their accumulation and decreased free fatty acid availability, leading to decreased mitochondrial $\beta$-oxidation and ATP production. Genetic inhibition of autophagy in HSCs attenuated liver fibrosis. A similar effect was seen in the fibrogenic cells from other tissues (lung, kidney, and embryonic fibroblasts) deriving from mice or humans. In the lecithin-retinol acyltransferase deficient mouse model, the absence of HSC retinoid droplets did not affect hepatic fibrosis in the BDL and $\mathrm{CCl}_{4}$ models, but it decreased carcinogenesis [84].

\section{The Role of the Gut Microbiome}

Chronic liver injury could be significantly perpetuated by extrahepatic causes. In NASH and alcoholic steatohepatitis, changes in the gut microbiota, increased intestinal permeability, and bacterial translocation significantly influence the inflammatory pathways in the liver $[85,86]$. The mucosal surface between the bacteria and the host immune system is responsible for the maintenance of innate and adaptive immune responses in order to maintain intestinal homeostasis. This function relies on the specific pattern recognition receptors, including TLRs and NODlike receptors that recognize the conserved microbial patterns termed pathogen-associated molecular patterns (PAMPs). One of the best-known PAMPs is lipopolysaccharide (LPS) deriving from Gram-negative bacteria. LPS was shown to activate TLR4 in Kupffer cells via the CD14 complex, resulting in the activation of JNK p38, interferon regulatory factor 3 , and NF- $\mathrm{NB}$ pathways $[87,88 \bullet$, which in turn results in the activation of proinflammatory pathways, including TNF- $\alpha$ and IL- $1 \beta$. HSCs are a crucial part of the TLR4-mediated signaling cascades as they respond to LPS by induction of NF- $\mathrm{KB}$ and JNK and stimulation of surface expression of intercellular adhesion molecule 1 and vascular cell adhesion molecule 1 [89]. Furthermore, the gut microbiota and TLR4 were shown to be important not only in fibrosis [88•] but also in liver carcinogenesis [90]. An interesting aspect of the role of gut microbiota was recently revealed by Henao-Mejia et al. [91]. In their study, defective NLRP6 and NLRP3 inflammasomes resulted in intestinal dysbiosis which was associated with progressive hepatic steatosis and inflammation through the influx of TLR4 and TLR9 agonists, leading to the upregulation of TNF- $\alpha$ expression in the liver. TLR2 has also been found to play a pivotal role in regulating intestinal microbiota and liver fibrosis [92]. On BDL, both TLR2 $2^{-/-}$and TNFRI ${ }^{-1-}$ mice showed reduced fibrosis, lower serum LPS levels, and decreased bacterial translocation. TNF- $\alpha$ activated the TNFRI on the intestinal epithelial cells and promoted gut permeability, facilitating bacterial translocation. The subsequent increase in the level of LPS in the circulation activated the TLR4 receptors on Kupffer cells, HSCs, and hepatocytes [92]. Therapeutic modulation of the intestinal microflora could thus be an alternative strategy to develop a novel antifibrotic therapy.

\section{MicroRNAs and HSC Activation}

MicroRNAs (miRNAs) are noncoding RNAs that regulate gene expression by specifically binding with the $3^{\prime}$ untranslated region of target gene messenger RNAs [93]. In terms of HSC activation, targeting the inhibition of the TGF- $\beta$ signaling pathway by miR-19b has shown great promise [94]. MiR-19b binding to the $3^{\prime}$ untranslated region of TGF- $\beta$ receptor II decreased the expression of type I collagen. In addition, the miR-29 family is emerging as a very important regulator of liver fibrosis. MiR-29b could be a novel regulator of type I collagen expression in addition to its involvement in the well-known Smad cascade by its interaction with SP1 expression. Overexpression of miR-29b suppressed the viability of primary, 
cultured mouse HSCs and the expression of $\alpha$-SMA [95]. Exosomes have emerged as carriers of extracellular miRNAs [96], and modulators of cell-cell interactions. In alcoholic liver disease, an increase in the levels of circulating miR-122 and miR-155 was seen, whereas the induction of miR-122 in the plasma after CpG treatment suggests that circulating miR-122 could be a marker of liver injury caused by DAMPs [97]. The clinical relevance of circulating miRNAs in fibrosis, however, still remains to be investigated.

\section{Epigenetic Modulation of HSC Activation}

Epigenetic changes including DNA methylation, histone modifications, and silencing by miRNAs significantly impact on wound healing and progression of fibrosis. According to current concepts, HSC transdifferentiation is facilitated by the repression of adipogenic genes such as peroxisome-proliferator-activated receptor $\gamma$ (PPAR $\gamma$ ),

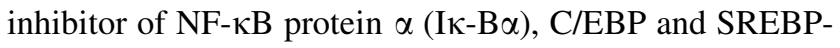
1c [98]. During HSC activation, the epigenetic repression of PPAR $\gamma$ is mediated by the depletion of miR-132, and this results in the induction of methyl-CpG binding protein $2(\mathrm{MeCP} 2)$ and its increased recruitment to the PPAR $\gamma$ promoter; whereas the enhancer of zeste homolog 2 (EZH2) causes histone methylation, preventing the recruitment of RNA polymerase II. Rosmarinic acid and baicalin have been shown to induce the de-repression of these pathways, also suppressing the canonical Wnt signaling [99]. An interesting concept is the epigenetic suppressive adaptation. It was shown that the history of liver damage corresponds with the transmission of an epigenetic suppression of the fibrogenesis in the liver in the offspring. This was hallmarked by the higher expression of PPAR $\gamma$ in the subsequent generation, and it was hypothesized that a myofibroblast-secreted soluble factor stimulated heritable epigenetic signatures in sperm, affecting the offspring's adaptation to future fibrogenic hepatic insults [100]. In this study it was also described that patients with mild liver fibrosis have PPAR $\gamma$ hypomethylation compared with patients with severe liver fibrosis. Better understanding of the epigenetic factors involved in liver fibrogenesis may shed light on the cause of the clinically observed susceptibility of patients to fibrogenic stimuli.

\section{Conclusion}

The complexity of fibrogenic pathways, their regulation, and the cross talk between the different cell types requires further studies in order to identify the core pathways involved in HSC activation. Identification and validation of these pathways will generate new therapeutic targets preventing or halting fibrosis progression and will reduce the complications of portal hypertension, thereby improving the quality of life and survival of patients with liver disease.

Disclosure Joy X. Jiang declares that she has no conflict of interest. Natalie J. Török has received research funding from Genkyotex and the National Institutes of Health.

Compliance with Ethics Guidelines This article does not contain any studies with human or animal subjects performed by any of the authors.

\section{References}

Recently published papers of particular importance have been highlighted as:

- Of importance

•- Of major importance

1. D’Amico G, Garcia-Tsao G, Pagliaro L (2006) Natural history and prognostic indicators of survival in cirrhosis: a systematic review of 118 studies. J Hepatol 44:217-231

2. Lee UE, Friedman SL (2011) Mechanisms of hepatic fibrogenesis. Best Pract Res Clin Gastroenterol 25:195-206

3. Wells RG (2013) Tissue mechanics and fibrosis. Biochim Biophys Acta 1832:884-890

4. Mormone E, George J, Nieto N (2011) Molecular pathogenesis of hepatic fibrosis and current therapeutic approaches. Chem Biol Interact 193:225-231

5. Wynn TA (2008) Cellular and molecular mechanisms of fibrosis. J Pathol 214:199-210

6. Cong M, Iwaisako K, Jiang C, Kisseleva T (2012) Cell signals influencing hepatic fibrosis. Int J Hepatol 2012:158547

7. Friedman SL (2000) Molecular regulation of hepatic fibrosis, an integrated cellular response to tissue injury. J Biol Chem 275:2247-2250

8. Buscemi L, Ramonet D, Klingberg F, Formey A, Smith-Clerc J, Meister JJ, Hinz B (2011) The single-molecule mechanics of the latent TGF-beta1 complex. Curr Biol 21:2046-2054

9. Benyon RC, Arthur MJ (2001) Extracellular matrix degradation and the role of hepatic stellate cells. Semin Liver Dis 21:373-384

10. Han YP (2006) Matrix metalloproteinases, the pros and cons, in liver fibrosis. J Gastroenterol Hepatol 21(Suppl 3):S88-S91

11. Kinnman N, Francoz C, Barbu V, Wendum D, Rey C, Hultcrantz R, Poupon R et al (2003) The myofibroblastic conversion of peribiliary fibrogenic cells distinct from hepatic stellate cells is stimulated by platelet-derived growth factor during liver fibrogenesis. Lab Invest 83:163-173

12. Bosselut N, Housset C, Marcelo P, Rey C, Burmester T, Vinh J, Vaubourdolle M et al (2010) Distinct proteomic features of two fibrogenic liver cell populations: hepatic stellate cells and portal myofibroblasts. Proteomics 10:1017-1028

13. Wells RG, Kruglov E, Dranoff JA (2004) Autocrine release of TGF-beta by portal fibroblasts regulates cell growth. FEBS Lett 559:107-110

14. Dranoff JA, Wells RG (2010) Portal fibroblasts: underappreciated mediators of biliary fibrosis. Hepatology 51:1438-1444 
15. Malhi H, Gores GJ (2008) Cellular and molecular mechanisms of liver injury. Gastroenterology 134:1641-1654

16. Malhi H, Gores GJ (2008) Molecular mechanisms of lipotoxicity in nonalcoholic fatty liver disease. Semin Liver Dis 28:360-369

17. Ibrahim SH, Kohli R, Gores GJ (2011) Mechanisms of lipotoxicity in NAFLD and clinical implications. J Pediatr Gastroenterol Nutr 53:131-140

18. Czaja MJ (2011) Two types of autophagy are better than one during hepatocyte oxidative stress. Autophagy 7:96-97

19. Amir M, Zhao E, Fontana L, Rosenberg H, Tanaka K, Gao G, Czaja MJ (2013) Inhibition of hepatocyte autophagy increases tumor necrosis factor-dependent liver injury by promoting caspase-8 activation. Cell Death Differ. doi:10.1038/cdd.2013.21

20. Ibrahim SH, Gores GJ (2012) Who pulls the trigger: JNK activation in liver lipotoxicity? J Hepatol 56:17-19

21. Nishitoh H (2012) CHOP is a multifunctional transcription factor in the ER stress response. J Biochem 151:217-219

22. Ji C, Kaplowitz N, Lau MY, Kao E, Petrovic LM, Lee AS (2011) Liver-specific loss of glucose-regulated protein 78 perturbs the unfolded protein response and exacerbates a spectrum of liver diseases in mice. Hepatology 54:229-239

23. Xu J, Lai KK, Verlinsky A, Lugea A, French SW, Cooper MP, Ji C et al (2011) Synergistic steatohepatitis by moderate obesity and alcohol in mice despite increased adiponectin and p-AMPK. J Hepatol 55:673-682

24. Saeed M, Suzuki R, Watanabe N, Masaki T, Tomonaga M, Muhammad A, Kato T et al (2011) Role of the endoplasmic reticulum-associated degradation (ERAD) pathway in degradation of hepatitis $\mathrm{C}$ virus envelope proteins and production of virus particles. J Biol Chem 286:37264-37273

25. Merquiol E, Uzi D, Mueller T, Goldenberg D, Nahmias Y, Xavier RJ, Tirosh B et al (2011) HCV causes chronic endoplasmic reticulum stress leading to adaptation and interference with the unfolded protein response. PLoS One 6:e24660

26. Reinehr R, Haussinger D (2012) CD95 death receptor and epidermal growth factor receptor (EGFR) in liver cell apoptosis and regeneration. Arch Biochem Biophys 518:2-7

27. - Guicciardi ME, Gores GJ (2010) Apoptosis as a mechanism for liver disease progression. Semin Liver Dis 30:402-410. The authors review the main pathways of apoptosis and its contribution to fibrosis

28. Elliott MR, Chekeni FB, Trampont PC, Lazarowski ER, Kadl A, Walk SF, Park D et al (2009) Nucleotides released by apoptotic cells act as a find-me signal to promote phagocytic clearance. Nature 461:282-286

29. Dranoff JA, Ogawa M, Kruglov EA, Gaca MD, Sevigny J, Robson SC, Wells RG (2004) Expression of P2Y nucleotide receptors and ectonucleotidases in quiescent and activated rat hepatic stellate cells. Am J Physiol Gastrointest Liver Physiol 287:G417-G424

30. Jiang JX, Venugopal S, Serizawa N, Chen X, Scott F, Li Y, Adamson $\mathrm{R}$ et al (2010) Reduced nicotinamide adenine dinucleotide phosphate oxidase 2 plays a key role in stellate cell activation and liver fibrogenesis in vivo. Gastroenterology 139:1375-1384

31. Canbay A, Feldstein AE, Higuchi H, Werneburg N, Grambihler A, Bronk SF, Gores GJ (2003) Kupffer cell engulfment of apoptotic bodies stimulates death ligand and cytokine expression. Hepatology 38:1188-1198

32. Watanabe A, Hashmi A, Gomes DA, Town T, Badou A, Flavell RA, Mehal WZ (2007) Apoptotic hepatocyte DNA inhibits hepatic stellate cell chemotaxis via toll-like receptor 9. Hepatology 46:1509-1518

33. Miura K, Kodama Y, Inokuchi S, Schnabl B, Aoyama T, Ohnishi H, Olefsky JM et al (2010) Toll-like receptor 9 promotes steatohepatitis by induction of interleukin-1beta in mice. Gastroenterology 139(323-334):e327

34. • Henao-Mejia J, Elinav E, Strowig T, Flavell RA (2012) Inflammasomes: far beyond inflammation. Nat Immunol 13:321-324. This is a recent update on the role of inflammasomes and their role in disease progression

35. Kono H, Rock KL (2008) How dying cells alert the immune system to danger. Nat Rev Immunol 8:279-289

36. Rodrigue-Gervais IG, Saleh M (2013) Caspases and immunity in a deadly grip. Trends Immunol 34:41-49

37. Rubartelli A, Gattorno M, Netea MG, Dinarello CA (2011) Interplay between redox status and inflammasome activation. Trends Immunol 32:559-566

38. • Kubes P, Mehal WZ (2012) Sterile inflammation in the liver. Gastroenterology 143:1158-1172. The authors provide a detailed and excellent summary on DAMP-induced sterile inflammation and inflammasome signaling in liver diseases

39. McDonald B, Pittman K, Menezes GB, Hirota SA, Slaba I, Waterhouse CC, Beck PL et al (2010) Intravascular danger signals guide neutrophils to sites of sterile inflammation. Science 330:362-366

40. Wang X, Sun R, Wei H, Tian Z (2013) High-mobility group box 1 (HMGB1)-Toll-like receptor (TLR)4-interleukin (IL)-23-IL17A axis in drug-induced damage-associated lethal hepatitis: Interaction of gammadelta $\mathrm{T}$ cells with macrophages. Hepatology $57: 373-384$

41. Wang X, Bu HF, Zhong W, Asai A, Zhou Z, Tan XD (2013) MFG-E8 and HMGB1 are involved in the mechanism underlying alcohol-induced impairment of macrophage engulfing apoptotic cells. Mol Med. doi:10.2119/molmed.2012.00260

42. Sato S, St-Pierre C, Bhaumik P, Nieminen J (2009) Galectins in innate immunity: dual functions of host soluble beta-galactoside-binding lectins as damage-associated molecular patterns (DAMPs) and as receptors for pathogen-associated molecular patterns (PAMPs). Immunol Rev 230:172-187

43. Henderson NC, Mackinnon AC, Farnworth SL, Poirier F, Russo FP, Iredale JP, Haslett C et al (2006) Galectin-3 regulates myofibroblast activation and hepatic fibrosis. Proc Natl Acad Sci USA 103:5060-5065

44. Jiang JX, Chen X, Hsu DK, Baghy K, Serizawa N, Scott F, Takada $Y$ et al (2012) Galectin-3 modulates phagocytosisinduced stellate cell activation and liver fibrosis in vivo. Am J Physiol Gastrointest Liver Physiol 302:G439-G446

45. Nomoto K, Nishida T, Nakanishi Y, Fujimoto M, Takasaki I, Tabuchi Y, Tsuneyama K (2012) Deficiency in galectin-3 promotes hepatic injury in CDAA diet-induced nonalcoholic fatty liver disease. ScientificWorldJournal 2012:959824

46. Iacobini C, Menini S, Ricci C, Blasetti Fantauzzi A, Scipioni A, Salvi L, Cordone $S$ et al (2011) Galectin-3 ablation protects mice from diet-induced NASH: a major scavenging role for galectin-3 in liver. J Hepatol 54:975-983

47. Dragomir AC, Sun R, Choi H, Laskin JD, Laskin DL (2012) Role of galectin-3 in classical and alternative macrophage activation in the liver following acetaminophen intoxication. J Immunol 189:5934-5941

48. Volarevic V, Milovanovic M, Ljujic B, Pejnovic N, Arsenijevic $\mathrm{N}$, Nilsson U, Leffler H et al (2012) Galectin-3 deficiency prevents concanavalin A-induced hepatitis in mice. Hepatology 55:1954-1964

49. MacKinnon AC, Farnworth SL, Hodkinson PS, Henderson NC, Atkinson KM, Leffler H, Nilsson UJ et al (2008) Regulation of alternative macrophage activation by galectin-3. J Immunol 180:2650-2658

50. Henderson NC, Sethi T (2009) The regulation of inflammation by galectin-3. Immunol Rev 230:160-171 
51. Dixon LJ, Flask CA, Papouchado BG, Feldstein AE, Nagy LE (2013) Caspase-1 as a central regulator of high fat diet-induced non-alcoholic steatohepatitis. PLoS One 8:e56100

52. Petrasek J, Bala S, Csak T, Lippai D, Kodys K, Menashy V, Barrieau $M$ et al (2012) IL-1 receptor antagonist ameliorates inflammasome-dependent alcoholic steatohepatitis in mice. J Clin Invest 122:3476-3489

53. Weng HL, Liu Y, Chen JL, Huang T, Xu LJ, Godoy P, Hu JH et al (2009) The etiology of liver damage imparts cytokines transforming growth factor beta1 or interleukin-13 as driving forces in fibrogenesis. Hepatology 50:230-243

54. Holt AP, Salmon M, Buckley CD, Adams DH (2008) Immune interactions in hepatic fibrosis. Clin Liver Dis 12:861-882, $\mathrm{x}$

55. Gordon S, Martinez FO (2010) Alternative activation of macrophages: mechanism and functions. Immunity 32:593-604

56. Meng F, Wang K, Aoyama T, Grivennikov SI, Paik Y, Scholten D, Cong M, et al. (2012) Interleukin-17 signaling in inflammatory, Kupffer cells, and hepatic stellate cells exacerbates liver fibrosis in mice. Gastroenterology 143:765-776 e761-763

57. Gao B, Radaeva S (2012) Natural killer and natural killer T cells in liver fibrosis. Biochim Biophys Acta 1832:1061-1069

58. Radaeva S, Wang L, Radaev S, Jeong WI, Park O, Gao B (2007) Retinoic acid signaling sensitizes hepatic stellate cells to NK cell killing via upregulation of NK cell activating ligand RAE1. Am J Physiol Gastrointest Liver Physiol 293:G809G816

59. Saile B, Eisenbach C, Dudas J, El-Armouche H, Ramadori G (2004) Interferon-gamma acts proapoptotic on hepatic stellate cells (HSC) and abrogates the antiapoptotic effect of interferonalpha by an HSP70-dependant pathway. Eur J Cell Biol 83: 469-476

60. Jeong WI, Park O, Gao B (2008) Abrogation of the antifibrotic effects of natural killer cells/interferon-gamma contributes to alcohol acceleration of liver fibrosis. Gastroenterology 134:248-258

61. Jeong WI, Park O, Suh YG, Byun JS, Park SY, Choi E, Kim JK et al (2011) Suppression of innate immunity (natural killer cell/ interferon-gamma) in the advanced stages of liver fibrosis in mice. Hepatology 53:1342-1351

62. - Tian Z, Chen Y, Gao B (2013) Natural killer cells in liver disease. Hepatology 57:1654-1662. The authors summarize the most advanced findings on the role of $\mathrm{NK}$ cells in liver diseases

63. Park O, Jeong WI, Wang L, Wang H, Lian ZX, Gershwin ME, Gao B (2009) Diverse roles of invariant natural killer T cells in liver injury and fibrosis induced by carbon tetrachloride. Hepatology 49:1683-1694

64. Syn WK, Oo YH, Pereira TA, Karaca GF, Jung Y, Omenetti A, Witek RP et al (2010) Accumulation of natural killer T cells in progressive nonalcoholic fatty liver disease. Hepatology 51: 1998-2007

65. Wehr A, Baeck C, Heymann F, Niemietz PM, Hammerich L, Martin C, Zimmermann HW et al (2013) Chemokine receptor CXCR6-dependent hepatic NK T cell accumulation promotes inflammation and liver fibrosis. J Immunol 190:5226-5236

66. Jaeschke H (2011) Reactive oxygen and mechanisms of inflammatory liver injury: present concepts. J Gastroenterol Hepatol 26(Suppl 1):173-179

67. Lieber CS (2004) Alcoholic fatty liver: its pathogenesis and mechanism of progression to inflammation and fibrosis. Alcohol 34:9-19

68. De Minicis S, Brenner DA (2007) NOX in liver fibrosis. Arch Biochem Biophys 462:266-272

69. Urtasun R, Lopategi A, George J, Leung TM, Lu Y, Wang X, Ge $\mathrm{X}$ et al (2012) Osteopontin, an oxidant stress sensitive cytokine, up-regulates collagen-I via integrin $\alpha_{\mathrm{V}} \beta_{3}$ engagement and PI3K/ pAkt/NFkB signaling. Hepatology 55:594-608
70. Novo E, Parola M (2012) The role of redox mechanisms in hepatic chronic wound healing and fibrogenesis. Fibrogenesis Tissue Repair 5(Suppl 1):S4

71. Hernandez-Gea V, Hilscher M, Rozenfeld R, Lim MP, Nieto N, Werner S, Devi LA et al (2013) Endoplasmic reticulum stress induces fibrogenic activity in hepatic stellate cells through autophagy. J Hepatol S0168-8278:001384-001394

72. Paik YH, Iwaisako K, Seki E, Inokuchi S, Schnabl B, Osterreicher $\mathrm{CH}$, Kisseleva $\mathrm{T}$ et al (2011) The nicotinamide adenine dinucleotide phosphate oxidase (NOX) homologues NOX1 and NOX2/gp91(phox) mediate hepatic fibrosis in mice. Hepatology 53:1730-1741

73. Cui W, Matsuno K, Iwata K, Ibi M, Matsumoto M, Zhang J, Zhu $\mathrm{K}$ et al (2011) NOX1/nicotinamide adenine dinucleotide phosphate, reduced form (NADPH) oxidase promotes proliferation of stellate cells and aggravates liver fibrosis induced by bile duct ligation. Hepatology 54:949-958

74. Sancho P, Mainez J, Crosas-Molist E, Roncero C, FernandezRodriguez CM, Pinedo F, Huber H et al (2012) NADPH oxidase NOX4 mediates stellate cell activation and hepatocyte cell death during liver fibrosis development. PLoS One 7:e45285

75. Kis K, Liu X, Hagood JS (2011) Myofibroblast differentiation and survival in fibrotic disease. Expert Rev Mol Med 13:e27

76. Jiang JX, Mikami K, Venugopal S, Li Y, Torok NJ (2009) Apoptotic body engulfment by hepatic stellate cells promotes their survival by the JAK/STAT and Akt/NF-kappaB-dependent pathways. J Hepatol 51:139-148

77. Aoyama T, Paik YH, Watanabe S, Laleu B, Gaggini F, FiorasoCartier L, Molango S et al (2012) Nicotinamide adenine dinucleotide phosphate oxidase in experimental liver fibrosis: GKT137831 as a novel potential therapeutic agent. Hepatology $56: 2316-2327$

78. Jiang JX, Chen X, Serizawa N, Szyndralewiez C, Page P, Schroder K, Brandes RP et al (2012) Liver fibrosis and hepatocyte apoptosis are attenuated by GKT137831, a novel NOX4/NOX1 inhibitor in vivo. Free Radic Biol Med 53:289-296

79. Omenetti A, Choi S, Michelotti G, Diehl AM (2011) Hedgehog signaling in the liver. J Hepatol 54:366-373

80. Robbins DJ, Fei DL, Riobo NA (2012) The Hedgehog signal transduction network. Sci Signal 5:re6

81. Choi SS, Omenetti A, Syn WK, Diehl AM (2011) The role of Hedgehog signaling in fibrogenic liver repair. Int $\mathrm{J}$ Biochem Cell Biol 43:238-244. This is a state-of-the art summary of the current knowledge of Hedgehog signaling in liver diseases

82. Chen Y, Choi SS, Michelotti GA, Chan IS, Swiderska-Syn M, Karaca GF, Xie G, et al. (2012) Hedgehog controls hepatic stellate cell fate by regulating metabolism. Gastroenterology 143:1319-1329.e11

83. Hernandez-Gea V, Ghiassi-Nejad Z, Rozenfeld R, Gordon R, Fiel MI, Yue Z, Czaja MJ et al (2012) Autophagy releases lipid that promotes fibrogenesis by activated hepatic stellate cells in mice and in human tissues. Gastroenterology 142:938-946

84. Kluwe J, Wongsiriroj N, Troeger JS, Gwak GY, Dapito DH, Pradere JP, Jiang H et al (2011) Absence of hepatic stellate cell retinoid lipid droplets does not enhance hepatic fibrosis but decreases hepatic carcinogenesis. Gut 60:1260-1268

85. Yan AW, Schnabl B (2012) Bacterial translocation and changes in the intestinal microbiome associated with alcoholic liver disease. World J Hepatol 4:110-118

86. Fouts DE, Torralba M, Nelson KE, Brenner DA, Schnabl B (2012) Bacterial translocation and changes in the intestinal microbiome in mouse models of liver disease. J Hepatol 56:1283-1292

87. Machado MV, Cortez-Pinto H (2012) Gut microbiota and nonalcoholic fatty liver disease. Ann Hepatol 11:440-449

88. - Seki E, Schnabl B (2012) Role of innate immunity and the microbiota in liver fibrosis: crosstalk between the liver and gut. 
J Physiol 590:447-458. The authors summarize the most important mechanisms by which the gut-liver axis is regulated

89. Paik YH, Schwabe RF, Bataller R, Russo MP, Jobin C, Brenner DA (2003) Toll-like receptor 4 mediates inflammatory signaling by bacterial lipopolysaccharide in human hepatic stellate cells. Hepatology 37:1043-1055

90. Dapito DH, Mencin A, Gwak GY, Pradere JP, Jang MK, Mederacke I, Caviglia JM et al (2012) Promotion of hepatocellular carcinoma by the intestinal microbiota and TLR4. Cancer Cell 21:504-516

91. Henao-Mejia J, Elinav E, Jin C, Hao L, Mehal WZ, Strowig T, Thaiss CA et al (2012) Inflammasome-mediated dysbiosis regulates progression of NAFLD and obesity. Nature 482:179-185

92. Hartmann P, Haimerl M, Mazagova M, Brenner DA, Schnabl B (2012) Toll-like receptor 2-mediated intestinal injury and enteric tumor necrosis factor receptor I contribute to liver fibrosis in mice. Gastroenterology 143(1330-1340):e1331

93. He Y, Huang C, Zhang SP, Sun X, Long XR, Li J (2012) The potential of microRNAs in liver fibrosis. Cell Signal 24:2268-2272

94. Lakner AM, Steuerwald NM, Walling TL, Ghosh S, Li T, McKillop IH, Russo MW et al (2012) Inhibitory effects of microRNA 19b in hepatic stellate cell-mediated fibrogenesis. Hepatology 56:300-310
95. Ogawa T, Iizuka M, Sekiya Y, Yoshizato K, Ikeda K, Kawada N (2010) Suppression of type I collagen production by microRNA$29 \mathrm{~b}$ in cultured human stellate cells. Biochem Biophys Res Commun 391:316-321

96. Vickers KC, Remaley AT (2012) Lipid-based carriers of microRNAs and intercellular communication. Curr Opin Lipidol 23:91-97

97. Bala S, Petrasek J, Mundkur S, Catalano D, Levin I, Ward J, Alao $\mathrm{H}$ et al (2012) Circulating microRNAs in exosomes indicate hepatocyte injury and inflammation in alcoholic, drug-induced, and inflammatory liver diseases. Hepatology 56:1946-1957

98. She H, Xiong S, Hazra S, Tsukamoto H (2005) Adipogenic transcriptional regulation of hepatic stellate cells. J Biol Chem 280:4959-4967

99. Yang MD, Chiang YM, Higashiyama R, Asahina K, Mann DA, Mann J, Wang CC et al (2012) Rosmarinic acid and baicalin epigenetically derepress peroxisomal proliferator-activated receptor gamma in hepatic stellate cells for their antifibrotic effect. Hepatology 55:1271-1281

100. Zeybel M, Hardy T, Wong YK, Mathers JC, Fox CR, Gackowska A, Oakley F et al (2012) Multigenerational epigenetic adaptation of the hepatic wound-healing response. Nat Med 18:1369-1377 